\title{
Mensuração e Análise da Construção de Capacidade Absortiva em Firmas Intensivas em Conhecimento em Minas Gerais
}

\section{Measurement and Analysis of Absorptive Capacity Building in Knowledge-Intensive Firms in Minas Gerais}

\author{
Diego Marcolino Lima Oliveira \\ Instituto Innovare de Pesquisa - Belo Horizonte - MG e PPGA-PUC Minas \\ diego.mldo@gmail.com \\ José Márcio de Castro \\ PPGA-PUC Minas \\ josemarcio@pucminas.br \\ Aléssia Franco Gonçalves \\ PPGA-PUC Minas \\ alessiafg@hotmail.com

\section{Christiene Mara dos Santos} \\ PPGA-PUC Minas \\ christieneconsultora@uol.com.br
}

\section{Artigo convidado}

\section{RESUMO}

Nas últimas décadas, a capacidade absortiva (CA) emergiu na literatura como um dos principais temas no campo da gestão sendo um construto utilizado na explicação de vários fenômenos organizacionais. Desde a década de 1990, quando a temática foi introduzida na análise organizacional, vários esforços foram empreendidos para compreender e analisar seus antecedentes e consequentes. Todavia, a literatura ainda ressente-se de maior compreensão empírica dos antecedentes da capacidade absortiva e das suas implicações para o gerenciamento da capacidade absortiva das firmas. Baseado em uma ampla revisão da literatura sobre os antecedentes da capacidade absortiva realizou-se uma survey com 155 firmas intensivas em conhecimento (KIB's) com vistas a construir e validar uma escala de mensuração da capacidade absortiva composta de 22 atributos. Além disso, com base na escala desenvolvida propusemos uma matriz de análise apontando os antecedentes (ou práticas organizacionais) que podem contribuir, nas firmas estudadas, para os processos de aquisição, assimilação, transformação e exploração dos conhecimentos externos para fins de inovação. Os resultados nas firmas pesquisadas indicam uma concentração de práticas organizacionais orientadas para o desenvolvimento da capacidade absortiva realizada (CAR) com várias implicações para a inovação das firmas.

Palavras-chave: Capacidade absortiva; Escala de mensuração; Antecedentes; Inovação 


\section{ABSTRACT}

In recent decades, the absorptive capacity (AC) has emerged in the literature as one of the main themes in the field of management being a construct used in the explanation of various organizational phenomena. Since the 1990s, when the theme was introduced in organizational analysis, various efforts have been made to understand and analyze its antecedents and consequents. However, the literature still resents itself of greater empirical understanding of the absorptive capacity antecedents and its implications for the management of firms' absorptive capacity. Based on a large literature review on the absorptive capacity antecedents, it was conducted a survey of 155 knowledge-intensive firms (KIBs) to create and validate an absorptive capacity measurement scale composed of 22 attributes.

Moreover, based on the developed scale, we proposed an analysis matrix showing the antecedents (or organizational practices) that can contribute in the studied firms, for the acquisition processes, assimilation, transformation and exploration of the external knowledge for innovation purposes. The results in the surveyed firms show a concentration of organizational practices oriented to develop the accomplished absorptive capacity (AAC) with several implications for the firms' innovation.

Keywords: Absorptive capacity; Measurement scale; Innovation; Antecedents

\section{Introdução}

O desafio de criar e manter vantagem competitiva tem levado as firmas a reconhecer o conhecimento como um dos principais ativos e diferenciais (BARNEY, 1991; CHEN; LOVVORN, 2011; PARK, VERTINSKY; BECERRA, 2014) sendo apontado, em várias pesquisas, como um valor relacionado com a inovação e performance da firma (PÉREZNORDTVEDT et al., 2008; VAN WIJK; JANSEN; LYLES, 2008). Nesses termos, a capacidade da firma de gerenciar o conhecimento e identificar fontes externas capazes de complementarem as suas habilidades e competências podem ampliar o seu potencial na construção de diferenciais estratégicos baseados no conhecimento (ARGOTE; FAHRENKOPF, 2016; ORTIZ, DONATE; GUADAMILLAS, 2016).

Nesse cenário, no qual as firmas dependem cada vez mais dos conhecimentos de fontes externas, a capacidade absortiva (CA) tornou-se um dos mais significativos construtos das últimas décadas (CAMISÓN; FORÉS, 2010) e um dos mais atraentes da pesquisa organizacional (DUCHEK, 2015). Esse entusiasmo não é sem razão quando se constata que a capacidade absortiva tem sido tomada como um construto central na compreensão de processos de transferência de conhecimento (MARTINKENAITE, 2011), na aprendizagem organizacional (KIM, 2004; ZAHRA; HAYTON, 2008), bem como para explicar a natureza e a dinâmica dos processos de inovação (LIAO; CHUANG; TO, 2011; CEPEDA-CARRIÓN, CEGARRA-NAVARRO; JIMENEZ-JIMENEZ, 2012; VEGA-JURADO et al., 2017).

Partindo da formulação clássica de Cohen e Levinthal (1990), Zahra e George (2002) conceberam a capacidade absortiva como a capacidade da firma em adquirir, assimilar, transformar e utilizar o conhecimento para gerar produtos, processos e serviços diferenciados. Todavia, mesmo com os avanços na compreensão da capacidade absortiva, os antecedentes que a influenciam ainda estão longe de um consenso e os processos da capacidade absortiva se assemelham a uma "caixa preta" (DUCHEK, 2015) com a literatura se ressentindo, ainda, de pesquisas empíricas mais aprofundadas sobre os antecedentes, que podem influenciar a capacidade absortiva. 
Sob tais considerações, o objetivo do artigo é o de propor um escala de mensuração da capacidade absortiva e, a partir daí, sugerir uma matriz analítica dos antecedentes de forma a permitir uma avaliação dos esforços da firma na construção da capacidade absortiva.

O estudo tem implicações teóricas e práticas. Do ponto de vista teórico, o artigo apresenta uma escala de mensuração testada e validada em uma amostra probabilística de firmas intensivas em conhecimento (KIB`s) de Minas Gerais. Além disso, é sugerida uma matriz de análise que permite avaliar os investimentos das firmas na construção da capacidade absortiva possibilitando a distinção de práticas e rotinas mais críticas. Do ponto de vista empírico, a avaliação das práticas que são mais relevantes na construção da capacidade absortiva pode levar as firmas a uma reconfiguração que pode influenciar mais decisivamente na aquisição, assimilação, transformação e exploração do conhecimento.

Para além dessa introdução, o artigo está organizado em outras quatro seções. $\mathrm{Na}$ segunda seção, discutimos o arcabouço teórico da capacidade absortiva e dos antecedentes. Em seguida apresentamos o método e procedimentos da pesquisa. Na quarta seção, apresentamos os dados, analisamos e sugerimos uma matriz de análise dos antecedentes. Finalmente, na última seção, apresentamos as conclusões, implicações e limitações da pesquisa.

\section{Revisão da Literatura}

\subsection{Capacidade Absortiva da Firma}

Referência seminal nos estudos de capacidade absortiva organizacional, Cohen e Levinthal (1990) a conceberam como a "(...) habilidade da firma em reconhecer o valor das novas informações externas, assimilá-las e aplica-las para fins comerciais (...)”. O ponto de partida dos autores foram os pressupostos da teoria da aprendizagem individual que, posteriormente, são traduzidos para o contexto organizacional (EASTERBY-SMITH et al., 2008). Nessa perspectiva, a aprendizagem organizacional é vista como uma função da capacidade absortiva (KIM, 2004).

Para Cohen e Levinthal (1990), o desenvolvimento da capacidade absortiva se assenta, prioritariamente, nos esforços de atividades internas de P\&D (Pesquisa \& Desenvolvimento), mas, também, na diversidade e amplitude da base de conhecimento e "(...) experiência de aprendizado anterior da firma, linguagem compartilhada, existência de interfaces funcionais e capacidade de resolução de problemas pelos membros das organizações (CAMISÓN; FORÉS, 2010 , p. 2)". Em outras palavras, a capacidade absortiva é maior naqueles campos nos quais a firma possui maior conhecimento e experiência prévia relacionada (HORVAT; DREHER; SOM, 2016; VEGA-JURADO et al., 2017).

Cohen e Levinthal (1990) argumentaram, ainda, que a capacidade absortiva dos indivíduos é determinante para a capacidade absortiva das firmas. Contudo, a capacidade absortiva não reside em nenhum indivíduo em particular, mas é tributária dos elos entre um mosaico de capacidades individuais (HORVAT; DREHER; SOM, 2016; VEGA-JURADO et al., 2017). Além disso, a capacidade absortiva depende, também, da facilidade com que o conhecimento flui e é transferido entre as unidades ou áreas estratégicas de uma organização (VEGA-JURADO et al., 2017). Em outros termos, a capacidade absortiva é altamente dependente das práticas organizacionais adotadas pelas firmas, seja para facilitar a identificação de conhecimentos externos relevantes, seja para promover os processos de compartilhamento intrafirmas (VEGA-JURADO et al., 2017).

Desde a sua introdução no campo organizacional, o conceito de capacidade absortiva foi reconceituado e estendido por numerosos estudos empíricos, entre os quais, o mais abrangente e de maior alcance como argumentam Camisón e Forés (2010) foi o modelo 
proposto por Zahra e George (2002) que se tornou o marco principal na literatura sobre capacidade absortiva. Nesse modelo, a capacidade absortiva é concebida como um conjunto de rotinas e processos ou, em outros termos, uma capacidade dinâmica que influencia a capacidade da firma em criar, adquirir e explorar o conhecimento para construir, modificar ou renovar as capacidades organizacionais (ZAHRA; GEORGE, 2002; CAMISÓN; FORÉS, 2010; DESCOTES; WALLISER, 2013; HORVAT; DREHER; SOM, 2016).

Em contraste com o modelo tridimensional clássico, Zahra e George (2002) reconceitualizam a capacidade absortiva em um modelo de quatro dimensões organizadas em torno de duas capacidades de absorção separadas: a capacidade absortiva potencial (CAP ou PACAP) e a capacidade absortiva realizada (CAR ou RACAP) contribuindo, assim, decisivamente, como apontam Horvat, Dreher e Som (2016), para a sua definição e operacionalização. Enquanto a capacidade absortiva potencial compreende as capacidades de aquisição e assimilação do conhecimento externo relevante e é a ponte entre a firma e o ambiente externo (FOSFURI; TRIBÓ, 2008), a capacidade absortiva realizada (RACAP) envolvem as capacidades de transformação e exploração do conhecimento, ou seja, é o elo entre a capacidade absortiva potencial e os resultados de inovação da firma (ZAHRA; GEORGE, 2002). Esses quatro componentes que se combinam e se complementam para a construção das capacidades organizacionais dinâmicas (CAMISÓN; FORÉS, 2010).

Embora separadas, as duas capacidades de absorção (potencial e realizada) são interdependentes e complementes (ZAHRA; GEORGE, 2002; VEGA-JURADO et al., 2017). Se por um lado, a capacidade absortiva potencial torna as firmas mais propensas à aquisição e assimilação do conhecimento, a capacidade absortiva realizada representa a capacidade da firma em alavancar o conhecimento absorvido por meio da transformação e exploração em produtos, processos e serviços (ZAHRA; GEORGE, 2002).

Nesses termos, a distinção entre capacidade absortiva potencial e realizada é singular na avaliação das contribuições de cada uma para o desenvolvimento da vantagem competitiva da firma. Assim, a ausência ou um baixo nível de uma ou de ambas as capacidades tem várias implicações para o desempenho das firmas. $\mathrm{O}$ fato de adquirir e assimilar o conhecimento não trará garantias de que o conhecimento será explorado para criar inovações em produtos e obter vantagem competitiva (GEORGE et al., 2001; VEGA-JURADO; GUTIÉRREZGRACIA; FERNÁNDEZ-DE-LUCIO, 2008). Assim, a firma deve ser capaz, também, de transformar e explorar o conhecimento ou, em outras palavras, transformá-lo em vantagem competitiva (CAMISÓN; FORÉS, 2010; FLATTEN et al., 2011).

As firmas com foco apenas na aquisição e assimilação de novos conhecimentos (PACAP) podem ser mais capazes de renovar continuamente a sua base de conhecimento (FOSFURI; TRIBÓ, 2008), de inovar em produtos e serviços ou de fazer adaptações exploratórias (JANSEN; VAN DEN BOSCH; VOLBERDA, 2005), mas, por outro lado, podem sofrer com custos de aquisição e assimilação sem obter os benefícios da exploração (ZAHRA; GEORGE, 2002; JANSEN; VAN DEN BOSCH; VOLBERDA, 2005; FOSFURI; TRIBÓ, 2008). De outro modo, as firmas que se orientam para a transformação e exploração (RACAP) podem alcançar lucros de curto prazo, mas podem cair na armadilha da competência e serem menos capazes de responder às mudanças ambientais (JANSEN; VAN DEN BOSCH; VOLBERDA, 2005; JIMENEZ-BARRIONUEVO; GARCIA-MORALES; MOLINA; 2011).

Para compreender ainda mais a capacidade absortiva e suas implicações para as firmas é necessário analisar os antecedentes que afetam as capacidade de aquisição e assimilação e transformação e exploração. 


\subsection{Antecedentes da Capacidade Absortiva da Firma}

\subsubsection{Antecedentes da Aquisição e Assimilação do Conhecimento}

A aquisição se refere à capacidade da firma de identificar e adquirir novos conhecimentos de fontes externas para as suas operações e é dependente de conhecimentos e experiências anteriores (JIMÉNEZ-CASTILLO; SÁNCHEZ-PÉREZ, 2013; VASCONCELOS et al., 2019) e é determinada pela intensidade, velocidade e direção da busca de conhecimento (COHEN; LEVINTHAL, 1990; ZAHRA; GEORGE, 2002). Como a capacidade absortiva está associada à natureza cumulativa da aprendizagem (COHEN; LEVINTHAL, 1990) quanto maior o conhecimento e a experiência anterior da firma no presente maior a sua capacidade futura para adquirir e explorar o conhecimento (dependência da trajetória) (VEGA-JURADO et al., 2017). Ou, de outro modo, quanto maior o esforço na busca de conhecimentos externos mais rapidamente e mais eficazmente a firma pode adquirir novas tecnologias (ZAHRA; GEORGE, 2002).

A aquisição de conhecimentos envolve rotinas e processos organizacionais que fornecem as bases para a identificação e a obtenção de conhecimentos externos relevantes pela firma (ZAHRA; GEORGE, 2002). Diversas práticas e rotinas organizacionais em linha com o ambiente externo funcionam como antecedentes da capacidade de aquisição de conhecimentos (NDIEGE; HERSELMAN; FLOWERDAY, 2012).

A base de conhecimento da firma tem sido destacada como um dos fatores centrais para o desenvolvimento da capacidade absortiva e tem sido analisada, principalmente, a partir dos esforços de P\&D (Pesquisa e Desenvolvimento) (VEGA-JURADO et al., 2017). Ou seja, o nível de investimentos em P\&D, assim como a intensidade dessas atividades na firma são considerados críticos para o desenvolvimento da capacidade absortiva, especialmente, para a capacidade absortiva potencial (CRISCUOLO; NARULA, 2008; VEGA-JURADO; GUTIÉRREZ-GRACIA; FERNÁNDEZ-DE-LUCIO, 2008). Atividades de P\&D, além de contribuírem para a inovação da firma, reforçam a trajetória tecnológica em uma determinada expertise (VEGA-JURADO et al., 2017). Seu papel na aquisição de conhecimentos é tornar a firma mais receptiva para reconhecer e absorver conhecimentos externos relevantes, bem como o de favorecer o aumento da base de conhecimento (COHEN; LEVINTHAL, 1990; VEGA-JURADO; GUTIÉRREZ-GRACIA; FERNÁNDEZ-DE-LUCIO, 2008). Ou seja, quanto maior o nível e a intensidade das atividades de $\mathrm{P} \& \mathrm{D}$, maior o impacto na capacidade de aquisição dos conhecimentos (COHEN; LEVINTHAL, 1990).

Contrariamente, investimentos escassos e descontínuos em atividades de $\mathrm{P} \& \mathrm{D}$ tendem a tornar a firma mais limitada em conhecimentos (SCHMIDT, 2010) podendo comprometer o desenvolvimento de novos conhecimentos a posteriori dado a natureza cumulativa da capacidade absortiva (COHEN; LEVINTHAL, 1990). Entretanto, como assinalam VegaJurado et al. (2018), embora não se possa negar o papel da P\&D para alavancar a capacidade de absorção, há setores industriais, particularmente, no contexto de pequenas e médias empresas de países emergentes, cujos recursos para tais atividades são escassos e, portanto, buscam informações complementares em seu ambiente como em fornecedores e clientes.

A qualidade das interações estabelecidas com clientes, fornecedores e parceiros, isto é, laços fortes, fortalecem os canais de informação e intensificam o fluxo de conhecimento entre as partes (NDIEGE; HERSELMAN; FLOWERDAY, 2012) e, por consequência, melhoram a capacidade de aquisição de novos conhecimentos ao fornecer às firmas visões sobre o estado do ambiente externo e novas oportunidades para melhorar os serviços aos clientes (NDIEGE; HERSELMAN; FLOWERDAY, 2012). Em muitos casos, essa é a alternativa para pequenas e médias empresas que não dispõem de recursos e não podem assumir os riscos de atividades de elevada incerteza (VEGA-JURADO et al., 2017). 
Outro antecedente relacionado à aquisição de conhecimentos é o vínculo ou envolvimento da firma com a comunidade científica. Tal como o desenvolvimento de $\mathrm{P} \& \mathrm{D}$, a aproximação dos colaboradores da firma com profissionais que realizam pesquisas científicas em universidades ou instituições de Ciência e Tecnologia (C\&T) é crítico para a identificação e absorção de conhecimentos externos relevantes (COCKBURN; HENDERSON, 1998; VEGA-JURADO; GUTIÉRREZ-GRACIA; FERNÁNDEZ-DE-LUCIO， 2008). Essa aproximação com profissionais das comunidades científicas permite à firma tirar proveito dos avanços científicos mais recentes (COCKBURN; HENDERSON, 1998). Além disso, firmas nas quais os colaboradores envolvidos em P\&D publicam em revistas científicos tendem a reconhecer com mais propriedade a existência de periódicos especializados nos quais há uma grande quantidade de conhecimentos disponíveis e úteis para as firmas (FOSFURI; TRIBÓ, 2008; VEGA-JURADO; GUTIÉRREZ-GRACIA; FERNÁNDEZ-DE-LUCIO, 2008).

Ainda com foco em relacionamentos, as interações informais com outras firmas ou instituições podem, também, favorecer o reconhecimento e aquisição de novos conhecimentos. Muitas atividades, incluindo a participação em feiras, eventos e programas de benchmarking são partes desses laços (TU et al., 2006). Na ausência de laços fracos, a firma priva-se de informações de lócus mais distantes do sistema social e fica confinada às informações dos seus laços mais diretos deixando de aproveitar o potencial de difusão de novas ideias, notícias e informações úteis originários dos laços mais tênues (GRANOVETTER, 1977, 1983).

Internamente à firma, existem, também, antecedentes relevantes que podem favorecer as capacidades de aquisição de novos conhecimentos. Por exemplo, na literatura, a participação dos colaboradores da firma no processo de tomada de decisão é apontada como capaz de elevar a quantidade de potenciais receptores de informações do ambiente externo que passam a agir seletivamente e atuar como facilitadores na obtenção de novos conhecimentos externos (VAN DEN BOSCH, VOLBERDA; BOER, 1999; JANSEN; VAN DEN BOSCH; VOLBERDA, 2005).

Finalmente, outro antecedente interno da aquisição é o nível de escolaridade dos colaboradores. Nesses termos, quanto maior a proporção de empregados com educação superior, pós-graduação, entre outros, maior a probabilidade de sucesso na aquisição de novos conhecimentos (VINDING, 2006). O argumento central é o de que colaboradores com elevada escolaridade estão em melhor posição para reconhecer e valorizar novos conhecimentos externos relevantes, o que pode contribuir para aumentar a base de conhecimentos da firma (VINDING, 2006).

Sinteticamente, os antecedentes mais relevantes na literatura existente relacionados à aquisição são: (i) nível de investimentos em P\&D; (ii) intensidade das atividades de P\&D; (iii) relações estreitas com clientes e fornecedores; (iv) Envolvimento com comunidade científica; (v) interações informais com outras firmas e instituições; (vi) participação dos colaboradores na tomada de decisão; e, (vii) nível de escolaridade dos colaboradores.

A assimilação, por sua vez consiste na capacidade da firma para analisar, interpretar e compreender os conhecimentos adquiridos externamente (VASCONCELOS et al., 2019). Uma vez reconhecido e absorvido, o desafio seguinte é compreender o conhecimento por meio de rotinas próprias e específicas (ZAHRA; GEORGE, 2002; JIMENEZBARRIONUEVO; GARCIA-MORALES; MOLINA; 2011) o que envolve, em grande parte, rotinas de disseminação e inteligência, bem como a gestão, permuta e compartilhamento de conhecimentos (FLATTEN et al., 2011). O papel dos antecedentes da capacidade de assimilação é reduzir as barreiras e contribuir para a intensidade de troca de conhecimento na firma (VEGA-JURADO; GUTIÉRREZ-GRACIA; FERNÁNDEZ-DE-LUCIO, 2008).

Um primeiro antecedente da assimilação é a existência de capacidades em tecnologia e sistemas de informação, como a utilização de memorandos, newsletters, intranet e e-mails está 
intimamente vinculada com a assimilação do conhecimento. São práticas indispensáveis para o armazenamento e distribuição eficiente do conhecimento (CEPEDA-CARRION; CEGARRA-NAVARRO; JIMENEZ-JIMENEZ, 2012) para nutrir os fluxos de informação qualificada (CHUNG; YUNG; MO 2014). A gestão da informação facilita a assimilação de novos conhecimentos, pois, entre outras coisas, evita contradições, aprimora a qualidade da informação percebida e fornece base para o desenvolvimento de interpretações compartilhadas do conhecimento por parte dos colaboradores da firma (JIMENEZCASTILLO; SANCHEZ-PEREZ, 2013b).

Outro antecedente que joga um papel relevante no desenvolvimento da capacidade de assimilação do conhecimento são os chamados multiplicadores (knowledge gatekeeper), pois, uma vez que sua ação é na interface entre a organização e o ambiente externo, promovem uma linguagem comum que pode ser compreendida por diferentes indivíduos, de diferentes unidades e áreas (COHEN; LEVINTHAL, 1990; SCHMIDT, 2010).

A estrutura organizacional tem, também, um papel relevante na assimilação dos novos conhecimentos (VAN DEN BOSCH; VOLBERDA; BOER, 1999; SCHMIDT, 2010). Uma estrutura mais flexível como a do tipo matricial ou por projetos, com critérios adhocráticos para o agrupamento de atividades e uma hierarquia funcional menos visível permite a alocação de colaboradores em diversos tipos de projetos favorecendo a troca, o fluxo de informações contínuo e, por conseguinte, maior assimilação do conhecimento VAN DEN BOSCH; VOLBERDA; BOER, 1999; VEGA-JURADO; GUTIÉRREZ-GRACIA; FERNÁNDEZ-DE-LUCIO, 2008).

A capacidade de assimilação também é positivamente relacionada com a constituição de equipes heterogêneas. Equipes compostas por indivíduos com diferentes formações, habilidades e sexo contribuem para a capacidade organizacional de integrar recursos cognitivos, superar diferenças, interpretar as questões e construir um entendimento coletivo e compartilhado do novo conhecimento externo (JANSEN; VAN DEN BOSCH; VOLBERDA, 2005).

Além desses, a presença de funcionários experientes em suas funções exercem maior influência sobre as capacidades inovadoras da organização, pois conseguem assimilar um novo conhecimento com maior facilidade (VINDING, 2006), e se constituem na interface entre o novo conhecimento e o conhecimento prévio em razão do conhecimento e experiência acumulados (COHEN; LEVINTHAL, 1990). Por fim, não se pode negligenciar a importância dos investimentos da firma em treinamento e qualificação, pois permite ao colaborador desenvolver habilidades específicas e atitudes para a melhoria do seu desempenho no trabalho. Em outras palavras, a assimilação de um novo conhecimento, além de ligada à experiência dos colaboradores, também, se associa ao volume e intensidade de treinamentos recebidos na função (MUROVEC; PRODAN, 2009; SCHMIDT, 2010).

Portanto, firmas com capacidades bem desenvolvidas de aquisição e assimilação serão mais hábeis na renovação contínua da base de conhecimento, detectando tendências em seu ambiente externo e internalizando esse conhecimento (FLOR; COOPER; OLTRA,. 2018). Pesquisando o efeito direto da capacidade absortiva no desempenho da inovação, resultados da pesquisa de Flor e Oltra (2018) apontam que vale a pena investir em processos e rotinas que facilitam a aquisição e assimilação do conhecimento externo para aumentar a inovação (FLOR; COOPER; OLTRA,. 2018).

Resumidamente, os antecedentes relacionados com a assimilação do conhecimento são: (i) capacidades de tecnologias e sistemas informação; (ii) Multiplicadores (knowledge gatekeeper); (iii) Estrutura organizacional da firma; (iv) equipes diversificadas; (v) colaboradores experientes; e, (vi) Investimentos em treinamento e qualificação. 


\subsubsection{Antecedentes da Transformação e Exploração do Conhecimento}

A transformação é a capacidade da firma de reconhecer dois conhecimentos aparentemente incongruentes (o externo e o previamente existente), combiná-los e gerar um novo conhecimento (VASCONCELOS et al., 2019). A transformação implica adição, filtragem, eliminação ou reinterpretação do conhecimento adquirido e assimilado (ZAHRA; GEORGE, 2002; CAMISÓM; FORÉS, 2010). Por outro lado, a exploração se refere à capacidade de utilizar o conhecimento transformado, integrando-o às operações da firma (VASCONCELOS et al., 2019). Um elemento relevante na exploração é a conversão dos conhecimentos em processos e rotinas que se tornam a base do desempenho superior da firma (CAMISÓN; FORÉS, 2010).

$\mathrm{Na}$ capacidade de transformação estão incluídas atividades que contribuem para o refinamento de rotinas e processos que favoreçam a combinação de conhecimentos oriundos de fontes externas. Um elemento vital na capacidade de transformação são os mecanismos de integração social (MIS) que contribuem para que os indivíduos, a partir do compartilhamento e troca, possam integrar bases de conhecimento e experiências existentes na firma com os conhecimentos adquiridos. Os mecanismos de integração social, por sua vez, se relacionam com as práticas de socialização que estimulam a criação de capital intelectual (FLATTEN et al., 2011).

Tais práticas podem envolver atividades formais e informais dependendo do grau de sistematização. Práticas de socialização como job rotation, círculos de qualidade e metodologias de resolução de problemas (JANSEN; VAN DEN BOSCH; VOLBERDA, 2005; FLATTEN et al., 2011) são antecedentes da capacidade de transformação que, primordialmente, fazem circular o conhecimento dentro das firmas contribuindo, dessa forma, para a redução do gap entre a capacidade absortiva potencial e a realizada (ZAHRA; GEORGE, 2002; JANSEN; VAN DEN BOSCH; VOLBERDA, 2005; EASTERBY-SMITH et al., 2008).

O papel específico da prática do job rotation consiste na transferência lateral de colaboradores entre as diversas funções e, por consequência, na mobilidade do conhecimento. Essa prática sugere que as experiências dos colaboradores são complementares, o que permite a cada indivíduo intensificar os conhecimentos e habilidades em áreas diversas da firma (COHEN; LEVINTHAL, 1990; ALLWOOD; LEE, 2004). São práticas que estimulam o compartilhamento de competências complementares e o desenvolvimento da capacidade dos colaboradores em aproveitar as oportunidades de transformação dos conhecimentos adquiridos externamente. Além disso, desenvolvem-se relações (laços) que ajudam a construir a coalização necessária para a transformação bem sucedida do conhecimento organizacional (JANSEN; VAN DEN BOSCH; VOLBERDA, 2005; VAN DEN BOSCH; VOLBERDA; BOER, 1999).

Por sua vez, os comitês de qualidade e de melhores práticas favorecem a solução de problemas, o compartilhamento de ideias, o estabelecimento de padrões, a criação de ferramentas e o fortalecimento de relações interpessoais (LIAO; CHUANG; TO, 2011). Como resultado dessas práticas tem-se o desenvolvimento de uma congruência de valores (confiança, reciprocidade e respeito), necessidades e crenças entre os indivíduos da organização, que estimulam a participação dos colaboradores e, por consequência, a transformação do conhecimento (JANSEN; VAN DEN BOSCH; VOLBERDA, 2005; VEGA-JURADO; GUTIÉRREZ-GRACIA; FERNÁNDEZ-DE-LUCIO, 2008).

Além das práticas de socialização, outros antecedentes podem favorecer a transformação do conhecimento. Como a disseminação do conhecimento na firma é relevante e nem sempre o local da aquisição e assimilação são os melhores locais para a transformação do conhecimento, programas de transferência do conhecimento intrafirma são críticos para a 
transformação. A título de exemplo, laboratórios de $\mathrm{P} \& \mathrm{D}$, reúnem informações sobre novas práticas, principalmente, porque mantém importantes conexões com fontes externas. Entretanto, a transformação desse conhecimento pode ocorrer em outros locais da firma (LENOX; KING, 2004).

Por fim, um ambiente interno que estimule a mudança, como por exemplo, a adoção de novos processos e rotinas favorece, também, a capacidade de transformação do conhecimento. Knox (2002) argumenta, por exemplo, que uma cultura e um clima organizacional propício podem encorajar o empreendedorismo individual e o trabalho em equipe na organização. Assim, a liberdade para expressar opiniões e a aprendizagem encorajada podem favorecer a avaliação e a combinação do conhecimento assimilado com o conhecimento existente na firma (KNOX, 2002; CEPEDA-CARRION; CEGARRANAVARRO; JIMENEZ-JIMENEZ, 2012).

De acordo com o que foi discutido, os principais antecedentes relacionados com a transformação do conhecimnto são: (i) Círculos de qualidade e comitês de melhores práticas para resolução de problemas; (ii) Job rotation; (iii) programas de transferência do conhecimento intrafirma; (iv) Liberdade para expressar opiniões; e (v) estímulos à aprendizagem.

A exploração do conhecimento, por sua vez, envolve a capacidade da firma em incorporar em suas operações e rotinas o conhecimento adquirido, assimilado e transformado (ZAHRA; GEORGE, 2002). Tal capacidade fornece, portanto, o suporte à criação de novos produtos, serviços e competências (JIMÉNEZ-CASTILLO; SÁNCHEZ-PÉREZ, 2013) e ou o aperfeiçoamento ou expansão dos já existentes (JIMENEZ-BARRIONUEVO; GARCIAMORALES; MOLINA; 2011; JIMÉNEZ-CASTILLO; SÁNCHEZ-PÉREZ, 2013).

O primeiro antecedente da exploração é a formalização que consiste no grau em que as regras, procedimentos, instruções e comunicações são estabelecidos formalmente, por escrito (JANSEN; VAN DEN BOSCH; VOLBERDA, 2005). A formalização de políticas, procedimentos e regras é crítica para a exploração do conhecimento (VEGA-JURADO; GUTIÉRREZ-GRACIA; FERNÁNDEZ-DE-LUCIO, 2008), uma vez que ao codificar as melhores práticas favorece a aplicação de um novo conhecimento acelerando o desenvolvimento de novos produtos, serviços e competências (JANSEN; VAN DEN BOSCH; VOLBERDA, 2005; VEGA-JURADO; GUTIÉRREZ-GRACIA; FERNÁNDEZ-DE-LUCIO, 2008).

A principal virtude da formalização é permitir aos colaboradores trocarem e combinarem conhecimentos explícitos por meio de mecanismos formais, facilitando a recuperação e o reuso do conhecimento já internalizado e aumentando a compreensão de conjuntos de tarefas dentro das unidades da firma (VAN DEN BOSCH; VOLBERDA; BOER, 1999). Além disso, a formalização reduz a necessidade de comunicação mais intensa entre uma unidade específica e a coordenação e cria uma memória organizacional que permite à firma atuar em situações de rotina (VAN DEN BOSCH; VOLBERDA; BOER, 1999; JANSEN; VAN DEN BOSCH; VOLBERDA, 2005; VEGA-JURADO; GUTIÉRREZGRACIA; FERNÁNDEZ-DE-LUCIO, 2008), o que, inclusive, pode acelerar a aprendizagem organizacional.

Diferentemente da formalização, o segundo antecedente da capacidade de exploração é se os colaboradores compreendem as regras e procedimentos formalizados (FLATTEN et al., 2011). O terceiro antecedente se refere ao grau em que a firma atende as necessidades dos clientes em produtos e serviços. Finalmente, os resultados da exploração do conhecimento dizem muito sobre as capacidades da firma. Assim, o quarto e último antecedente da capacidade de exploração são as saídas inovadoras como patentes, copyrigths e direitos autorais (FLATTEN et al., 2011; DASPIT; D'SOUZA, 2013) e produtos, processos e serviços (FALTTEN et al., 2011). 
Em síntese, os principais antecedentes relacionados com a exploração do conhecimento são: (i) Formalização regras, procedimentos, instruções e comunicações; (ii) compreensão pelos colaboradores das regras e procedimentos; (iii) tradução das necessidades dos clientes em novos produtos e serviços; e (iv) Resultados da exploração do conhecimento externo.

O Quadro 1 sintetiza o conjunto de antecedentes discutidos na literatura que podem influenciar as capacidades de aquisição, assimilação, transformação e exploração do conhecimento pelas firmas.

Quadro 1 - Síntese Teórica dos Antecedentes da Capacidade Absortiva Potencial e Realizada

\begin{tabular}{|c|c|c|}
\hline Dimensões & Componentes da CA & Antecedentes \\
\hline \multirow{2}{*}{$\begin{array}{c}\text { Capacidade } \\
\text { Absortiva Potencial }\end{array}$} & Aquisição & $\begin{array}{l}\text { Nível de investimentos em P\&D; } \\
\text { Intensidade das atividades de P\&D } \\
\text { Relações estreitas com clientes e fornecedores } \\
\text { Envolvimento com comunidade científica } \\
\text { Interações informais com firmas e instituições } \\
\text { Participação na tomada de decisão } \\
\text { Nível de escolaridade dos colaboradores }\end{array}$ \\
\hline & Assimilação & $\begin{array}{l}\text { Capacidades tecnologias/sistemas informação } \\
\text { Multiplicadores (knowledge gatekeeper) } \\
\text { Estrutura organizacional da firma } \\
\text { Equipes diversificadas } \\
\text { Colaboradores experientes } \\
\text { Investimentos em treinamento e qualificação }\end{array}$ \\
\hline \multirow{2}{*}{$\begin{array}{c}\text { Capacidade } \\
\text { Absortiva Realizada }\end{array}$} & Transformação & 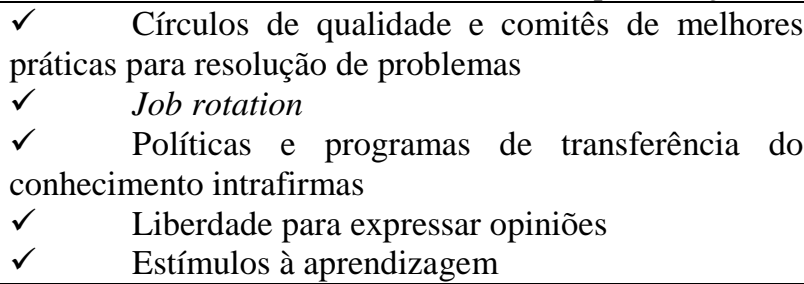 \\
\hline & Exploração & $\begin{array}{ll}\checkmark & \text { Formalização de regras e procedimentos } \\
\checkmark & \text { Compreensão pelos colaboradores das regras e } \\
\text { procedimentos } \\
\checkmark & \text { Tradução das necessidades dos clientes em } \\
\text { novos produtos e serviços } \\
\checkmark & \text { Resultados da exploração do conhecimento } \\
\text { externo } & \end{array}$ \\
\hline
\end{tabular}

Fonte: Elaborado pelos autores

\section{Método}

Para analisar os antecedentes que explicam a capacidade absortiva da firma, a pesquisa utilizou uma estratégia quantitativa, de corte transversal, por meio do método do survey, que é adequado, principalmente, quando se quer testar empiricamente uma teoria (BABBIE, 2003).

O objeto da pesquisa são organizações intensivas em conhecimentos (KIB’s) de Minas Gerais. Para definir a população de organizações intensivas em conhecimento, considerou-se o critério utilizado na Pesquisa Industrial de Inovação Tecnológica (Pintec), realizada pelo Instituto Brasileiro de Geografia Estatística (IBGE). (IBGE, 2011).

Além da atividade econômica, a composição da população-alvo de interesse da pesquisa também considerou alguns critérios para a seleção da amostra de firmas, a saber: (i) estar localizada no Estado de Minas Gerais; (ii) possuir registro ativo no Cadastro Nacional de Pessoa Jurídica (CNPJ); (iii) ter dez ou mais pessoas ocupadas durante o período de coleta 
dos dados; e (iv) ter pelo menos um ano de existência. Além disso, para garantir que apenas organizações intensivas em conhecimento participassem da pesquisa, definiu-se que fariam parte da amostra aquelas firmas que, nos último ano, se envolveram em atividades internas de $\mathrm{P} \& \mathrm{D}$, adquiriram $\mathrm{P} \& \mathrm{D}$ externamente, adquiriram outros conhecimentos externos (exploração de patentes, aquisição de know-how e outros tipos de conhecimento técnico-científico), compraram softwares, introduziram inovações tecnológicas no mercado ou se envolveram em projetos industriais e outras preparações técnicas para a produção e distribuição.

Para o tamanho da população-alvo e a definição dos estratos amostrais consultaram-se dados da RAIS de 2013 que indicaram a existência de 946 firmas, Minas Gerais, que atuavam nos setores de interesse desta pesquisa. Utilizando-se de uma amostra probabilística (LOHR, 2009) com uma amostragem estratificada (MALHOTRA, 2012) estabeleceu-se o tamanho mínimo da amostra aleatória de 155 organizações, considerando-se uma margem de erro (ME) arbitrariamente fixada em 4,9\% e um intervalo de confiança (IC), também arbitrário, de 95\%.

Nesta pesquisa, os estratos foram estabelecidos por grupos de atividades econômicas, a saber: (i) setor de produtos químicos, farmoquímicos e farmacêuticos; (ii) setor de equipamentos de informática, produtos eletrônicos e ópticos; (iii) setor automotivo; e (iv) outros. Os elementos de cada estrato foram selecionados por um processo aleatório simples de maneira que em cada grupo os elementos da população tivessem a mesma probabilidade de serem amostrados (LOHR, 2009; MALHOTRA, 2012).

O instrumento de coleta de dados foi elaborado a partir da revisão da literatura sobre antecedentes da capacidade absortiva. Após o pré-teste e adequações do instrumento passouse à aplicação dos questionários que foi feita por meio de entrevistas telefônicas. Cada respondente na empresa amostrada deveria ocupar um cargo de liderança em áreas específicas (como, por exemplo, tecnologia, estratégia ou produtos), respondendo sobre seu nível de concordância com as afirmações com base em uma escala do tipo Likert de dez pontos. Além disso, para reforçar a qualidade dos dados coletados, alguns procedimentos de checagem foram adotados, a saber: (i) acompanhamento do entrevistador ao longo da aplicação dos questionários; (ii) gravação das entrevistas telefônicas; (iii) checagem de $40 \%$ das entrevistas feitas, isto é, foi realizado um novo contato com 62 respondentes para confirmar a aplicação do questionário, bem como as respostas dadas.

A técnica de extração dos atributos e das dimensões foi feita a partir da análise de componentes principais, cujo objetivo é produzir combinações de atributos que capturem o máximo possível a variância nos atributos observados (HAIR et al., 2006). Primeiramente, as definições de quais atributos conseguiam explicar o construto foi baseada nas comunalidades. Usualmente, o valor mínimo aceitável é de 0,50. Logo, na ocorrência de comunalidades abaixo desse patamar, a variável era excluída e a análise fatorial realizada novamente (HAIR et al., 2006).

Para definir a quantidade de dimensões latentes da capacidade absortiva, a pesquisa baseou-se no critério de Kaiser (regra de eigenvalue). Esse método sugere que devem persistir apenas dimensões com valor de eigenvalue acima de um, posto que um baixo eigenvalue sugere uma dimensão que contribui pouco para explicar a variância nas variáveis observadas (FIGUEIREDO; SILVA, 2010; HAIR et al., 2006).

Por fim, para determinar quais atributos seriam carregados e em quais dimensões, optou-se pela rotação ortogonal varimax selecionando atributos que apresentam elevadas cargas explicativas (cargas fatoriais) em cada dimensão latente (HAIR et al., 2006). Em outras palavras, cada atributo contribui para explicar a variância em apenas uma dimensão, e quanto maior seu resultado, maior é seu potencial explicativo. Assim, buscou-se definir os antecedentes mais relevantes para compreender a capacidade absortiva em organizações intensivas em conhecimento de Minas Gerais. 


\section{Resultados}

\subsection{Caracterização da Amostra}

$\mathrm{Na}$ amostra pesquisa, os resultados apontam que a aquisição de conhecimentos externos (patentes, aquisição de know-how ou outros tipos de conhecimento técnicocientífico) é a atividade mais citada. Além disso, $71 \%$ das firmas se envolveram com P\&D no último ano, cerca de 70\%, das firmas estudadas, nesse mesmo período, adquiriram P\&D externamente. Entretanto, não se observou uma frequência elevada de introdução de inovações tecnológicas no mercado.

Figura 1: Características das empresas intensivas em conhecimento (em \%)

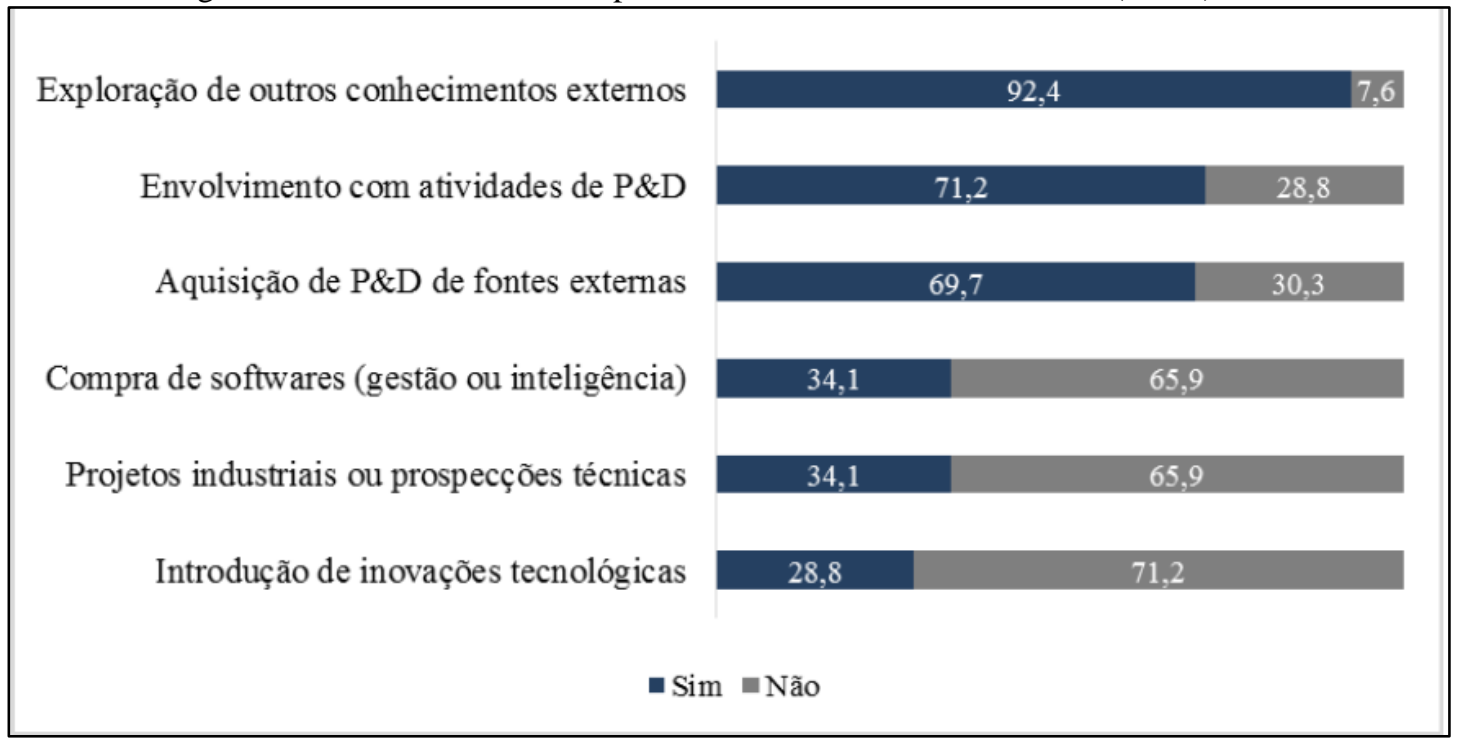

Fonte: Dados da pesquisa

Em relação aos respondentes, destaca-se que todos ocupam cargos de liderança, a saber: (i) diretores; (ii) gerentes; (iii) coordenadores ou (iv) supervisores. Além disso, conforme a Figura 3, os entrevistados são de áreas estratégicas e ligadas à inovação e ao conhecimento, tais como Recursos Humanos, Marketing, Planejamento, Produtos, dentre outros. Observou-se ainda que, em média, cada respondente possui uma experiência de cinco anos no cargo.

Figura 2: Características dos respondentes

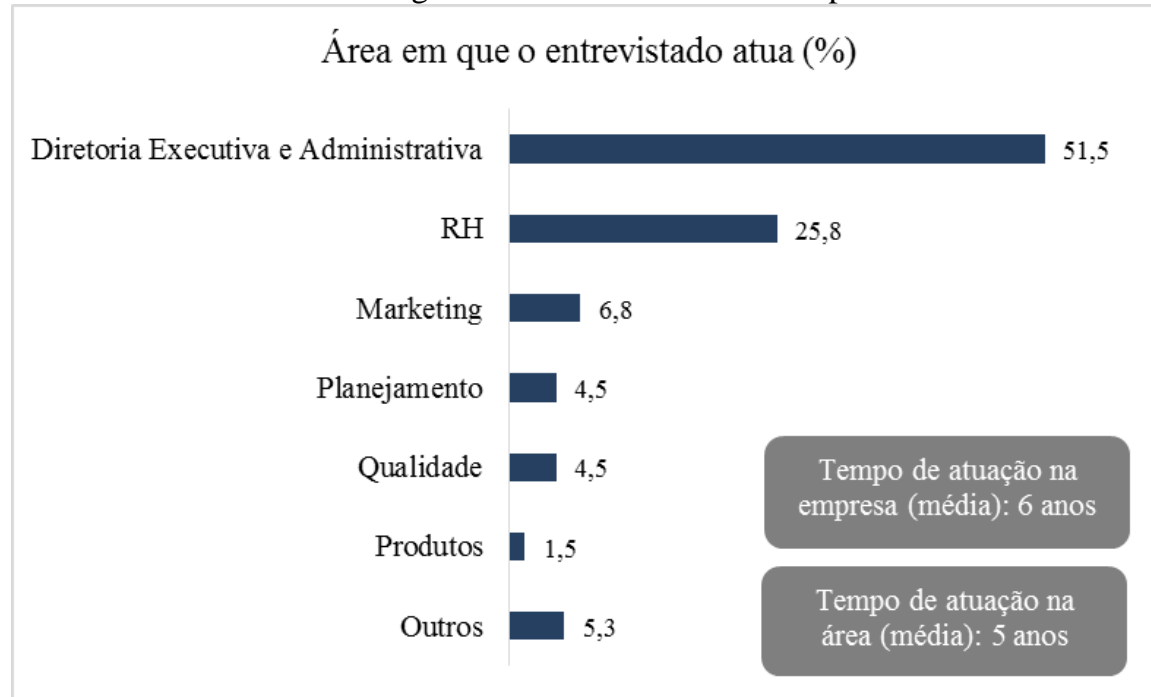

Fonte: Dados da pesquisa 


\subsection{Antecedentes da Capacidade Absortiva das Firmas}

No Quadro 2, apresentam-se os antecedentes que explicam a capacidade absortiva das organizações intensivas em conhecimento de Minas Gerais. Os resultados endossam o modelo de Zahra e George (2002) ao confirmarem as duas dimensões para a capacidade absortiva: potencial e realizada.

Quadro 2 - Os Antecedentes da Capacidade Absortiva

\begin{tabular}{|c|c|c|c|c|c|}
\hline Dimensão & Atividade & Antecedentes & $\begin{array}{l}\text { Carga } \\
\text { fatorial }\end{array}$ & Média & $\sigma(*)$ \\
\hline \multirow{12}{*}{ PACAP } & \multirow{2}{*}{$\begin{array}{l}\text { Aquisição }-\mathrm{P} \& \mathrm{D} \\
\text { (eigenvalue: } 1,663 \text { ) }\end{array}$} & Nível de investimentos em P\&D & 0,842 & 5,40 & 2,73 \\
\hline & & Intensidade das atividades internas de P\&D & 0,839 & 5,31 & 2,57 \\
\hline & \multirow{3}{*}{$\begin{array}{c}\text { Aquisição - } \\
\text { Educação e } \\
\text { Treinamento } \\
\text { (eigenvalue: } 1,471 \text { ) }\end{array}$} & Envolvimento com a comunidade científica & 0,801 & 5,26 & 2,64 \\
\hline & & Colaboradores com elevada escolaridade & 0,749 & 6,48 & 2,11 \\
\hline & & $\begin{array}{l}\text { Investimento em treinamento e qualificação } \\
\text { (Treinamento on the job) }\end{array}$ & 0,523 & 7,36 & 1,32 \\
\hline & \multirow{2}{*}{$\begin{array}{l}\text { Aquisição - Clientes } \\
\text { e Fornecedores } \\
\text { (eigenvalue: } 1,038 \text { ) }\end{array}$} & $\begin{array}{l}\text { Relações estreitas com fornecedores e demais } \\
\text { parceiros }\end{array}$ & 0,740 & 7,87 & 1,42 \\
\hline & & Relações estreitas com os clientes & 0,739 & 7,98 & 1,30 \\
\hline & \multirow{5}{*}{$\begin{array}{c}\text { Assimilação } \\
\text { (eigenvalue: } 1,845)\end{array}$} & $\begin{array}{l}\text { Estrutura organizacional que favorece a } \\
\text { permuta de conhecimento }\end{array}$ & 0,781 & 6,86 & 1,46 \\
\hline & & $\begin{array}{l}\text { Experiência dos colaboradores em suas } \\
\text { funções }\end{array}$ & 0,672 & 6,99 & 1,50 \\
\hline & & $\begin{array}{l}\text { Habilidades em tecnologias e sistemas da } \\
\text { informação (Compartilhamento coordenado } \\
\text { da informação, por meio de sistemas e } \\
\text { tecnologias da informação) }\end{array}$ & 0,664 & 7,41 & 1,52 \\
\hline & & $\begin{array}{l}\text { Interações informais com demais empresas } \\
\text { (em feiras, eventos, etc.) }\end{array}$ & 0,604 & 7,27 & 1,89 \\
\hline & & $\begin{array}{l}\text { Existência de multiplicadores do } \\
\text { conhecimento (gatekeeper) }\end{array}$ & 0,590 & 6,80 & 1,62 \\
\hline \multirow{10}{*}{ RACAP } & \multirow{6}{*}{$\begin{array}{l}\text { Transformação } \\
\text { (eigenvalue: } 2,200)\end{array}$} & $\begin{array}{l}\text { Políticas que facilitam transferir } \\
\text { conhecimento dentro da organização }\end{array}$ & 0,787 & 7,11 & 1,43 \\
\hline & & Constituição de equipes diversificadas & 0,783 & 6,79 & 1,87 \\
\hline & & $\begin{array}{l}\text { Criação de círculos de qualidade e melhores } \\
\text { práticas para resolução de problemas }\end{array}$ & 0,754 & 7,13 & 1,68 \\
\hline & & $\begin{array}{l}\text { Liberdade para expressar dúvidas, críticas e } \\
\text { sugestões }\end{array}$ & 0,748 & 7,61 & 1,28 \\
\hline & & Prática de job rotation & 0,650 & 6,27 & 2,28 \\
\hline & & $\begin{array}{l}\text { Valorização da aprendizagem e dos riscos } \\
\text { assumidos, minimizando os eventuais erros }\end{array}$ & 0,592 & 7,56 & 1,30 \\
\hline & \multirow{4}{*}{$\begin{array}{c}\text { Exploração } \\
\text { (eigenvalue: } 6,198)\end{array}$} & $\begin{array}{l}\text { Tradução das necessidades dos clientes em } \\
\text { novos produtos, serviços ou processos }\end{array}$ & 0,783 & 7,63 & 1,44 \\
\hline & & $\begin{array}{l}\text { Elevado nível de formalização, em manuais, } \\
\text { regras ou procedimentos }\end{array}$ & 0,630 & 7,52 & 1,85 \\
\hline & & $\begin{array}{l}\text { Compreensão dos funcionários sobre as } \\
\text { regras e procedimentos }\end{array}$ & 0,584 & 7,55 & 1,41 \\
\hline & & $\begin{array}{l}\text { Lançamentos de patentes, copyrights ou } \\
\text { direitos autorais }\end{array}$ & 0,408 & 5,02 & 2,80 \\
\hline
\end{tabular}

Fonte: Dados da pesquisa

$(*) \sigma$. Desvio- padrão

Para se chegar à escala final, algumas especificidades em relação aos resultados foram observadas culminando no rearranjo de alguns dos antecedentes. A primeira especificidade se relaciona à capacidade de aquisição de novos conhecimentos externos. Esta atividade, de acordo com os resultados, foi dividida em três atributos: (i) relacionados com P\&D; (ii) 
relacionados com educação e treinamento; e (iii) que envolvem a relação das firmas com clientes e fornecedores e parceiros.

De acordo com os resultados da análise fatorial, o atributo "Treinamento on the job", originalmente tratado na literatura como constituínte da capacidade de assimilação (SCHMIDT, 2010) foi mais aderente na explicação da capacidade de aquisição de novos conhecimentos. Em contrapartida, o atributo que trata das "Interações informais com outras empresas" que, na literatura, é parte da capacidade de aquisição, parece explicar melhor as variações da capacidade de assimilação sendo, portanto, remanejado. $O$ atributo "Diversificação da equipe" inicialmente integrante da capacidade de assimilação, obteve maior aderência e foi deslocado para a capacidade de transformação do conhecimento adquirido. Por fim, em relação ao atributo "Participação na tomada de decisão" não foram encontradas variações significativas na capacidade absortiva das firmas investigadas decorrentes desse atributo e, assim, tal atributo não entrou no modelo de mensuração.

Os dados do Quadro 2 também revelam, por meio do eigenvalue, aspectos relevantes sobre a relevância ou impacto que cada atividade possui na explicação das variações na capacidade absortiva das firmas. A partir dos dados, pode-se afirmar que a exploração, por exemplo, é atividade que mais explica a variância da capacidade absortiva, seguido pela transformação. Isso sugere que a capacidade absortiva realizada é a dimensão com maior orientação na amostra investigada.

As cargas fatoriais, por sua vez, apontam o poder explicativo de cada atributo em sua respectiva capacidade. Desse modo, destaca-se a importância do atributo envolvimento com atividades de $\mathrm{P} \& \mathrm{D}$. Muito embora esse envolvimento não explique totalmente a aquisição de novos conhecimentos externos, ele apresenta uma carga fatorial próxima de 1, ou seja, um alto poder explicativo na capacidade de aquisição. A estrutura organizacional, por sua vez, é o atributo que mais explica a assimilação dos conhecimentos adquiridos externamente. Em outras palavras, uma estrutura flexível permite maior interação entre os funcionários, colaborando para uma compreensão comum do conhecimento adquirido.

Em termos gerais, observa-se que as práticas relacionadas à aquisição de conhecimento são as que apresentam pior desempenho, principalmente, aquelas relacionadas com o desenvolvimento e intensidade de P\&D e escolaridade dos colaboradores. Além disso, estas práticas, também, apresentaram desvios padrões elevados indicando uma maior discrepância entre os resultados dos amostrados. Em outras palavras, no que se refere à aquisição de conhecimento externo por meio da $\mathrm{P} \& \mathrm{D}$, elevada escolaridade dos colaboradores e envolvimento com a comunidade científica, não raro, encontram-se organizações com um alto desempenho convivendo com outras nas quais não se observam avaliações tão positivas.

Se de um lado, a aquisição de conhecimento por meio de $\mathrm{P} \& \mathrm{D}$, educação e treinamento são as que apresentam os piores desempenhos, por outro lado, é mais comum entre as organizações amostradas a aquisição de conhecimento externo por meio da interação com clientes e fornecedores e outros parceiros que apresentaram um desempenho mais elevado.

Por outro lado, a assimilação e a transformação, são capacidades que envolvem práticas (antecedentes) com desempenho médio próximo de 7 (escala de 1 a 10) entre as firmas. No entanto, observa-se que a prática de "job rotation", constituinte da atividade de transformação, apresenta um desempenho médio inferior às demais, e com os resultados mais discrepantes entre os amostrados.

Para transformar o conhecimento adquirido e assimilado em um novo conhecimento, quatro atributos ganham destaque e apresentam cargas fatoriais bastante similares, a saber: (i) políticas que facilitam a transferência do conhecimento dentro da organização; (ii) constituição de equipes diversificadas; (iii) criação de comitês de qualidade e melhores 
práticas e (iv) valorização da aprendizagem e dos riscos assumidos, minimizando os eventuais erros.

Por fim, a tradução das necessidades dos clientes em novos produtos, serviços ou processos é o que mais explica a capacidade de exploração, ou seja, este atributo é o que mais determina se a firma utiliza o conhecimento adquirido, assimilado e transformado para fins comerciais. Todavia, observa-se, ainda, que a capacidade de exploração tem elevado nível de formalização e compreensão de regras e procedimento pelos colaboradores, mas em relação ao atributo "Obtenção de patentes, copyrights ou direitos autorias" o desempenho é fraco.

Os dados parecem sugerir, portanto, que a baixa performance em inovação das organizações intensivas em conhecimento de Minas Gerais está relacionada com dificuldades em adquirir conhecimento externo relevante, seja por carência de atividades em P\&D ou pelo baixo envolvimento com a comunidade científica, estando o foco da aquisição de conhecimentos mais orientado para as interações com clientes, fornecedores e parceiros.

\subsection{Matriz de Análise da Capacidade Absortiva}

A partir da escala de mensuração da capacidade absortiva testada e validada em uma amostra de 155 firmas intensivas em conhecimento (KIB’s), foi elaborado um modelo de análise da capacidade absortiva das firmas considerando-se dois continuum: um eixo vertical que vai de baixo a alto e indica o desempenho de cada um dos antecedentes da capacidade absortiva nas firmas intensivas em conhecimento; $\mathrm{O}$ outro, no eixo horizontal que vai de baixo a alto e indica o poder explicativo de cada antecedente (carga fatorial). A média dos resultados dos antecedentes e a média de suas cargas fatoriais foram utilizadas para a definição dos quadrantes da matriz de análise.

Assim, no quadrante inferior esquerdo (Quadrante I) estão os antecedentes (práticas organizacionais) com desempenho abaixo da média no conjunto das firmas pesquisadas. No quadrante superior esquerdo (Quadrante II) estão os antecedentes (práticas organizacionais) com desempenho acima da média, mas cujo impacto na capacidade absortiva é inferior à média. Em contrapartida, no quadrante superior direito (Quadrante III - Pontos Fortes) estão os antecedentes (práticas organizacionais) com alto impacto na CA e cujo desempenho observado nas firmas intensivas em conhecimento está acima da média. Finalmente, no quadrante inferior direito (Quadrante IV - Prioridade) estão plotados os antecedentes cujo impacto na capacidade absortiva é acima da média, porém, o desempenho desses antecedentes no conjunto das firmas encontra-se abaixo da média.

Considerando-se os dados do Quadro 2 e a matriz de análise dos antecedentes da capacidade absortiva, tem-se que no quadrante inferior esquerdo (Quadrante I), encontram-se as práticas que merecem investimentos adicionais, pois estão com o desempenho inferior à média. No entanto, esse investimento pode ficar para um momento posterior, já que outras rotinas e processos contribuem mais decisivamente para o desenvolvimento da capacidade absortiva das firmas. Tais rotinas e processos são: (i) Existência de multiplicadores do conhecimento e (ii) Prática de job rotation. (iii) Lançamentos de patentes, copyrights ou direitos autorais.

No quadrante superior esquerdo (Quadrante II), encontram-se as práticas que devem ser mantidas, mas que não demandam novos investimentos, uma vez que a contribuição para o desenvolvimento da capacidade absortiva é menos significativo. São elas: (i) Treinamento on the job; (ii) Valorização da aprendizagem e dos riscos assumidos, minimizando os eventuais erros; (iii) Compreensão dos funcionários sobre as regras e procedimentos; (iv) Interações informais com demais empresas; (v) Elevado nível de formalização, em manuais, regras ou procedimentos; (vi) Compartilhamento coordenado da informação, por meio de 
sistemas e tecnologias da informação; e (vii) Experiência dos colaboradores em suas funções. Em razão desses resultados não se plotou esses antecedentes nos quadrantes I e II na matriz.

Os quadrantes seguintes, por sua vez, são merecedores de destaque. Primeiramente, no quadrante superior direito (Quadrante III), encontram-se as práticas com alto impacto na capacidade absortiva das firmas pesquisadas, e com um desempenho acima da média. Por isso é denominado de "Quadrante pontos fortes" ao revelar as rotinas e processos que mais favorecem a capacidade absortiva e, consequentemente, a inovação das firmas. No quadrante inferior direito, denominado de "Quadrante prioridade", estão plotadas as práticas que tem impacto acima da média e desempenho abaixo da média. Trata-se, portanto, de práticas que devem ser intensificadas nas firmas pesquisadas, de modo a aprimorar a capacidade absortiva e incentivar saídas inovadoras.

Figura 3: A Matriz dos antecedentes nas firmas intensivas em conhecimento

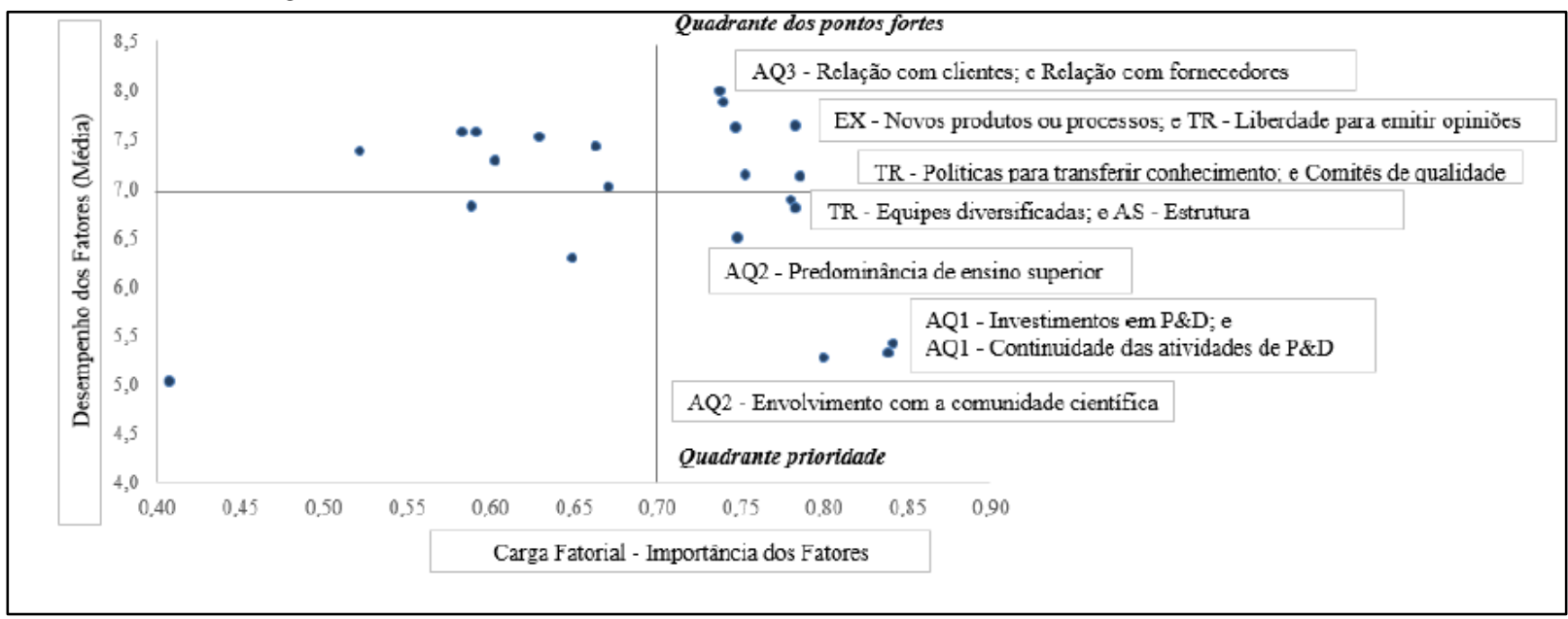

Fonte: Dados da pesquisa

Desse modo, conforme poder ser observado na Figura 3, torna-se evidente uma predominância de práticas constituintes da capacidade absortiva potencial no "Quadrante prioridade", isto é, principalmente, antecedentes relacionados à aquisição, que tem desempenho abaixo da média no conjunto das firmas investigadas. Neste quadrante estão rotinas e processos que envolvem a aquisição de conhecimento externo, seja por meio de atividades de $\mathrm{P} \& \mathrm{D}$, educação formal e envolvimento com a comunidade científica.

Esta carência na aquisição de conhecimento externo é minimizada, em parte, pela interação que as firmas mantêm com clientes e fornecedores e parceiros. Tais práticas fazem parte do quadrante de pontos fortes. As organizações amostradas, portanto, conseguem combinar os conhecimentos existentes com aqueles adquiridos externamente. Para isso, observa-se a importância mecanismos de integração social de natureza formal como os comitês de qualidade e políticas que facilitam transferir conhecimento, bem como os mecanismos informais que garantem a liberdade dos funcionários em expressarem opiniões, sugestões ou dúvidas. Com isso, as organizações mineiras lançam novos produtos e serviços, mas sem muito apelo de inovação.

Em outras palavras, o que se observa, de fato, é uma concentração de práticas constituintes da CAP no quadrante de prioridades. Em contrapartida, nos pontos fortes, notase predominância de rotinas e processos da CAR. Desse modo, desenvolver a dimensão potencial da capacidade absortiva torna-se relevante para evitar cair na armadilha da competência e incapacidade de responder às mudanças no ambiente de negócios (JANSEN; VAN DEN BOSCH; VOLBERDA, 2005) 


\section{Conclusões}

Um primeiro resultado se refere à elaboração e teste de uma escala de mensuração da capacidade absortiva. Partindo da discussão dos antecedentes na literatura encontrou-se um conjunto de 22 atributos assim distribuídos: aquisição (7), assimilação (5), transformação (6) e exploração (4).

$\mathrm{Na}$ análise das firmas intensivas em conhecimento (KIB`s) em Minas Gerais encontrou-se um baixo investimento na construção de capacidades de aquisição e assimilação (capacidade absortiva potencial) e um maior desenvolvimento da capacidade absortiva realizada.

Esse resultado representa, em princípio, um paradoxo, uma vez que em firmas intensivas em conhecimento (KIB's) esperava-se um resultado diferente. Por exemplo, na análise geral, em termos de aquisição de conhecimento há um baixo investimento em atividades de $\mathrm{P} \& \mathrm{D}$, o que dificulta a aquisição de novos conhecimentos externos. Ao invés disso, uma das fontes principais de obtenção de informações externas é por meio dos relacionamentos com clientes e fornecedores e parceiros. Veja-Jurado et al. (2018) aponta que, empresas pequenas e médias, principalmente, em economias emergentes, são avessas aos riscos e aos custos da $\mathrm{P} \& \mathrm{D}$ e tendem a focar a aquisição de conhecimentos a partir desses relacionamentos. Todavia, uma ressalva é importante: há, na amostra da pesquisa, empresas com elevados investimentos em P\&D e outras de baixo investimento.

O baixo nível de capacidade absortiva potencial tem algumas implicações: (i) as firmas tem poucas saídas inovadoras, o que é confirmado com os resultados da capacidade de exploração; (ii) baixo investimento das firmas na construção de uma base de conhecimento, que pode implicar obsolescência e dificuldades para adaptação às mudanças do ambiente no futuro; (iii) por consequência, necessidade de investir em capacidades de aquisição e assimilação cujos antecedentes tem alto impacto e estão abaixo da média em desempenho (ZAHRA; GEORGE, 2002; JANSEN; VAN DEN BOSCH; VOLBERDA, 2005; FOSFURI; TRIBÓ, 2008)

O presente artigo tem contribuições teóricas e gerenciais. Do ponto de vista teórico, a partir de uma extensa revisão da literatura e com o emprego de estatísticas multivariadas, elencaram-se 22 antecedentes que explicam a capacidade absortiva de firmas intensivas em conhecimento de Minas Gerais. Essa escala, embora testada em uma amostra significativa, deve ser objeto de novos testes futuros. Tais antecedentes, portanto, podem ajudar a entender o desempenho destas organizações em reconhecer, assimilar, transformar e explorar um conhecimento externo relevante. Sobre este aspecto, inclusive, os resultados estão de acordo com a literatura e indicam que, de fato, a capacidade absortiva é um construto multidimensional, que se divide em uma dimensão potencial e outra realizada.

$\mathrm{O}$ artigo também possui contribuições gerenciais ao apresentar uma matriz de análise da capacidade absortiva. Com essa matriz, torna-se possível identificar os pontos fortes, bem como priorizar ações para a construção de capacidade absortiva das firmas, a partir da escala apresentada.

Por fim, as limitações do estudo envolvem a ampliação do universo pesquisado. Em outras palavras, em pesquisas futuras, convém replicar este estudo em outros universos, com estágios ou desenvolvimento econômicos diferentes. Assim, é possível comparar o que deve ser priorizado em empresas com diferentes níveis de CA. Além disso, novos estudos, com uma abordagem qualitativa, podem compreender melhor como estes atributos estão relacionados entre si, isto é, aprofundar no papel dos mecanismos de integração social e sua relação na conversão de PACAP em RACAP. 


\section{REFERÊNCIAS}

ALLWOOD, J. M.; LEE, Wee Leong. The impact of job rotation on problem solving skills. International Journal of Production Research, v. 42, n. 5, p. 865-881, 2004.

ARGOTE, Linda; FAHRENKOPF, Erin. Knowledge transfer in organizations: The roles of members, tasks, tools, and networks. Organizational Behavior and Human Decision Processes, v. 136, p. 146-159, 2016.

BABBIE, Earl. Métodos de pesquisa de survey. 2a reimpr. UFMG, Belo Horizonte, 2003.

BARNEY, Jay. Firm resources and sustained competitive advantage. Journal of management, v. 17, n. 1, p. 99-120, 1991.

CAMISÓN, César; FORÉS, Beatriz. Knowledge absorptive capacity: New insights for its conceptualization and measurement. Journal of Business Research, v. 63, n. 7, p. 707-715, 2010.

CEPEDA-CARRION, Gabriel; CEGARRA-NAVARRO, Juan G.; JIMENEZ-JIMENEZ, Daniel. The effect of absorptive capacity on innovativeness: Context and information systems capability as catalysts. British Journal of Management, v. 23, n. 1, p. 110-129, 2012.

CHEN, Jiun-Shiu; LOVVORN, Al S. The speed of knowledge transfer within multinational enterprises: the role of social capital.International Journal of Commerce and Management, v. 21, n. 1, p. 46-62, 2011.

COCKBURN, Iain M.; HENDERSON, Rebecca M. Absorptive capacity, coauthoring behavior, and the organization of research in drug discovery. The Journal of Industrial Economics, v. 46, n. 2, p. 157-182, 1998.

COHEN, Wesley M.; LEVINTHAL, Daniel A. Absorptive capacity: A new perspective on learning and innovation. Administrative science quarterly, v. 35, n. 1, p. 128-152, 1990.

CRISCUOLO, Paola; NARULA, Rajneesh. A novel approach to national technological accumulation and absorptive capacity: aggregating Cohen and Levinthal. The European Journal of Development Research, v. 20, n. 1, p. 56-73, 2008.

DASPIT, Joshua J.; D' SOUZA, Derrick E. Understanding the multi-dimensional nature of absorptive capacity. Journal of Managerial Issues, p. 299-316, 2013.

DESCOTES, Raluca M.; WALLISER, Björn. Foreign market-related knowledge absorption and the international financial performance of SMEs. Management international/International Management/Gestiòn Internacional, v. 17, n. 4, p. 178-193, 2013.

DUCHEK, Stephanie. Enhancing absorptive capacity for innovation and change: The role of structural determinants. Journal of Change Management, v. 15, n. 2, p. 142-160, 2015.

EASTERBY-SMITH, Mark et al. Absorptive capacity: A process perspective. Management learning, v. 39, n. 5, p. 483-501, 2008.

FLATTEN, Tessa C. et al. A measure of absorptive capacity: Scale development and validation. European Management Journal, v. 29, n. 2, p. 98-116, 2011.

FLOR, M. Luisa; COOPER, Sarah Y.; OLTRA, María J. External knowledge search, absorptive capacity and radical innovation in high-technology firms. European Management Journal, v. 36, n. 2, p. 183-194, 2018.

FOSFURI, Andrea; TRIBÓ, Josep A. Exploring the antecedents of potential absorptive capacity and its impact on innovation performance. Omega, v. 36, n. 2, p. 173-187, 2008.

GEORGE, Gerard et al. The effects of alliance portfolio characteristics and absorptive capacity on performance: A study of biotechnology firms. The Journal of High Technology Management Research, v. 12, n. 2, p. 205-226, 2001.

GRANOVETTER, Mark S. The strength of weak ties. In: Social networks. Academic Press, 1977. p. 347-367. 
GRANOVETTER, Mark. The strength of weak ties: A network theory revisited. 1983.

HAIR, Joseph F. et al. Multivariate data analysis 6th Edition. Pearson Prentice Hall. New Jersey. 2006.

IBGE. Pesquisa Industrial - Inovação Tecnológica - Pintec 2011. Análise dos Resultados. Rio de Janeiro: 2011.

IMD. World Competitiveness Yearbook International Institute for Management Development, Lausanne, 2015.

JANSEN, Justin JP; VAN DEN BOSCH, Frans AJ; VOLBERDA, Henk W. Managing potential and realized absorptive capacity: how do organizational antecedents matter? Academy of management journal, v. 48, n. 6, p. 999-1015, 2005.

JIMÉNEZ-BARRIONUEVO, María Magdalena; GARCÍA-MORALES, Víctor J.; MOLINA, Luis Miguel. Validation of an instrument to measure absorptive capacity. Technovation, v. 31, n. 5-6, p. 190-202, 2011.

JIMÉNEZ-CASTILLO, David; SÁNCHEZ-PÉREZ, Manuel. Market knowledge absorptive capacity: a measurement scale. Information Research, v. 18, n. 4, p. 1-17, 2013.

NDIEGE, Joshua R.; HERSELMAN, Marlien E.; FLOWERDAY, Stephen V. Absorptive capacity: Relevancy for large and small enterprises. South African Journal of Information Management, v. 14, n. 1, p. 1-9, 2012.

KIM, Linsu. Crisis construction and organizational learning. Managing Strategic Innovation and Change: A Collection of Readings, Oxford University Press US, v. 375, 2004.

KNOX, Simon. The boardroom agenda: developing the innovative organisation. Corporate Governance: The international journal of business in society, v. 2, n. 1, p. 27-36, 2002.

HORVAT, Djerdj; DREHER, Carsten; SOM, Oliver. Absorptive Capacity: Opening the Black Box from a Process Perspective. In: ISPIM Conference Proceedings. The International Society for Professional Innovation Management (ISPIM), 2016. p. 1.

LENOX, Michael; KING, Andrew. Prospects for developing absorptive capacity through internal information provision. Strategic management journal, v. 25, n. 4, p. 331-345, 2004. LIAO, Chechen; CHUANG, Shu-Hui; TO, Pui-Lai. How knowledge management mediates the relationship between environment and organizational structure. Journal of business research, v. 64, n. 7, p. 728-736, 2011.

LOHR, Sharon L. Sampling: Design and AnalysisChapman and Hall/CRC, 2009.

MALHOTRA, Naresh K. Pesquisa de Marketing-: Uma Orientação Aplicada. Bookman Editora, 2012.

MARTINKENAITE, Ieva. Antecedents and consequences of inter-organizational knowledge transfer: Emerging themes and openings for further research. Baltic Journal of Management, v. 6, n. 1, p. 53-70, 2011.

MUROVEC, Nika; PRODAN, Igor. Absorptive capacity, its determinants, and influence on innovation output: Cross-cultural validation of the structural model. Technovation, v. 29, $\mathrm{n}$. 12, p. 859-872, 2009.

ORTIZ, Beatriz; DONATE, Mario J.; GUADAMILLAS, Fátima. Relational and cognitive social capital: Their influence on strategies of external knowledge acquisition. Procedia Computer Science, v. 99, p. 91-100, 2016.

PARK, Chansoo; VERTINSKY, Ilan; BECERRA, Manuel. Transfers of tacit vs. explicit knowledge and performance in international joint ventures: The role of age. International Business Review, v. 24, n. 1, p. 89-101, 2015.

PÉREZ-NORDTVEDT, Liliana et al. Effectiveness and efficiency of cross-border knowledge transfer: An empirical examination. Journal of Management Studies, v. 45, n. 4, p. 714-744, 2008. 
SCHMIDT, Tobias. Absorptive capacity - one size fits all? A firm-level analysis of absorptive capacity for different kinds of knowledge. Managerial and Decision Economics, v. 31, n. 1, p. 1-18, 2010.

TU, Qiang et al. Absorptive capacity: Enhancing the assimilation of time-based manufacturing practices. Journal of operations management, v. 24, n. 5, p. 692-710, 2006.

VAN DEN BOSCH, FAJ; VOLBERDA, Henk W.; BOER, M. de. Coevolution of firm absorptive capacity and knowledge environment: organizational forms and combinative capabilities. Organization Science, v. 10, n. 5, p. 551-568, 1999.

VAN WIJK, Raymond; JANSEN, Justin JP; LYLES, Marjorie A. Inter-and intraorganizational knowledge transfer: a meta-analytic review and assessment of its antecedents and consequences. Journal of management studies, v. 45, n. 4, p. 830-853, 2008.

VASCONCELOS, Ana Cristina et al. Absorptive capacity: A process and structure approach. Journal of Information Science, v. 45, n. 1, p. 68-83, 2019.

VEGA-JURADO, Jaider M.; GUTIÉRREZ-GRACIA, Antonio; FERNÁNDEZ-DE-LUCIO, Ignacio. Analyzing the determinants of firm's absorptive capacity: beyond R\&D. R\&d Management, v. 38, n. 4, p. 392-405, 2008.

VEGA-JURADO, Jaider M. et al. La base de conocimiento y su impacto en la capacidad de absorción de pymes de baja tecnología. Cuadernos de Administración, v. 30, n. 55, p. 7-35, 2017.

VINDING, Anker L.. Absorptive capacity and innovative performance: A human capital approach. Economics of innovation and New Technology, v. 15, n. 4-5, p. 507-517, 2006.

VOLBERDA, Henk W.; FOSS, Nicolai J.; LYLES, Marjorie A. Perspective-Absorbing the concept of absorptive capacity: How to realize its potential in the organization field. Organization science, v. 21, n. 4, p. 931-951, 2010.

ZAHRA, Shaker A.; GEORGE, Gerard. Absorptive capacity: A review, reconceptualization, and extension. Academy of management review, v. 27, n. 2, p. 185-203, 2002.

ZAHRA, Shaker A.; HAYTON, James C. The effect of international venturing on firm performance: The moderating influence of absorptive capacity. Journal of business venturing, v. 23, n. 2, p. 195-220, 2008. 